\title{
Lung transplantation in China: a firm foundation for a solid future
}

\author{
Shambhu Aryal, Steven D. Nathan \\ Inova Advanced Lung Disease and Lung Transplant Program, Inova Fairfax Hospital, Falls Church, VA, USA \\ Correspondence to: Steven D. Nathan. 3300 Gallows Rd, Falls Church, VA 22042, USA. Email: Steven.nathan@inova.org. \\ Provenance and Peer Review: This article was commissioned and reviewed by Section Editor Jianfei Shen, MD (Taizhou Hospital of Zhejiang Province, \\ Wenzhou Medical University, Taizhou, China). \\ Comment on: Wu B, Hu C, Chen W, et al. China lung transplantation developing: past, present and future. Ann Transl Med 2020;8:41.
}

Submitted Jan 22, 2020. Accepted for publication Feb 14, 2020.

doi: 10.21037/atm.2020.02.165

View this article at: http://dx.doi.org/10.21037/atm.2020.02.165

Editorials typically are geared towards original research and placing this in the appropriate context for readers. In this case, we have been asked and are privileged to provide an editorial on a review of the history and status of lung transplantation in China. Lung transplantation is an established therapy for most end-stage lung diseases refractory to medical therapy. Over 35 years have passed since the first successful lung transplantation performed in Toronto, Canada (1). The number of lung transplants has since steadily increased in most Western countries with about 4,500 lung transplants reported to the International Society for Heart and Lung Transplantation (ISLHT) in 2017 (Figure 1) (2). At the same time, many centers around the world are building lung transplant programs to meet the needs of their patients $(3,4)$. In this issue of Annals of Translational Medicine, Dr. Wu and colleagues from different lung transplant centers in China, provide a comprehensive review of lung transplantation in the country over the past 40 years (5).

The authors have performed an admirable job in providing an overview of the history of lung transplantation in general and how this has developed in China. They provide appropriate commendations to the early international and local pioneers of lung transplantation. The article opens a window into how lung transplantation has developed and grown in China; it is noteworthy that it's evolution and the accompanying regulatory oversight has largely escaped the notice of the international lung transplant community. Specifically, it is gratifying to note that laws have been enacted to support the development of qualified transplant centers, limit the illegal use of organs (including volitional donation only) and prohibit transplant tourism.

The China Lung Transplantation Registry (CLuTR) is a welcome resource that was established in 2011. One- and three-year survivals from this are reported at $70.11 \%$ and $61.16 \%$, respectively (6). The 1 -year survival in particular in lower than that reported in the ISHLT Registry for the same period; specifically from the ISHLT Registry, for the era of 2010-June 2017, the 1 and 3 years survivals were $84.8 \%$ and $70.3 \%$, respectively $(\mathrm{n}=29,872)(2)$. What can be gleaned from this? Since no further insight is provided into first year outcomes, it is difficult to know if this early post-transplant attrition is related to recipient selection/ comorbidities, donor preservation or other technical issues. However, it is gratifying that once patients make it past 1 year, their conditional survivals are equivalent. One advantage of the CLuTR will be to not only document these outcomes, but to also hopefully enable a "deep dive" into the cause of this lower 1-year survival and establish best practice guidelines that might be unique to China. For example, according to the first Chinese National Registry report of lung transplantation in 2016, infection was the main complication in the early postoperative period (6); an expected complication that could be improved with better early identification and treatment.

Over a period of 4 years (2015 to 2018), there were just over 1,000 lung transplants recorded by the CLuTR, for an average of 250 cases per year. There seems to have been a rapid growth in the number of transplants particularly over the last few years in two of the major centers, Wuxi Hospital and China-Japan Friendship Hospital. This does raise the question of what the ceiling might be for the number of transplants that could be performed in 


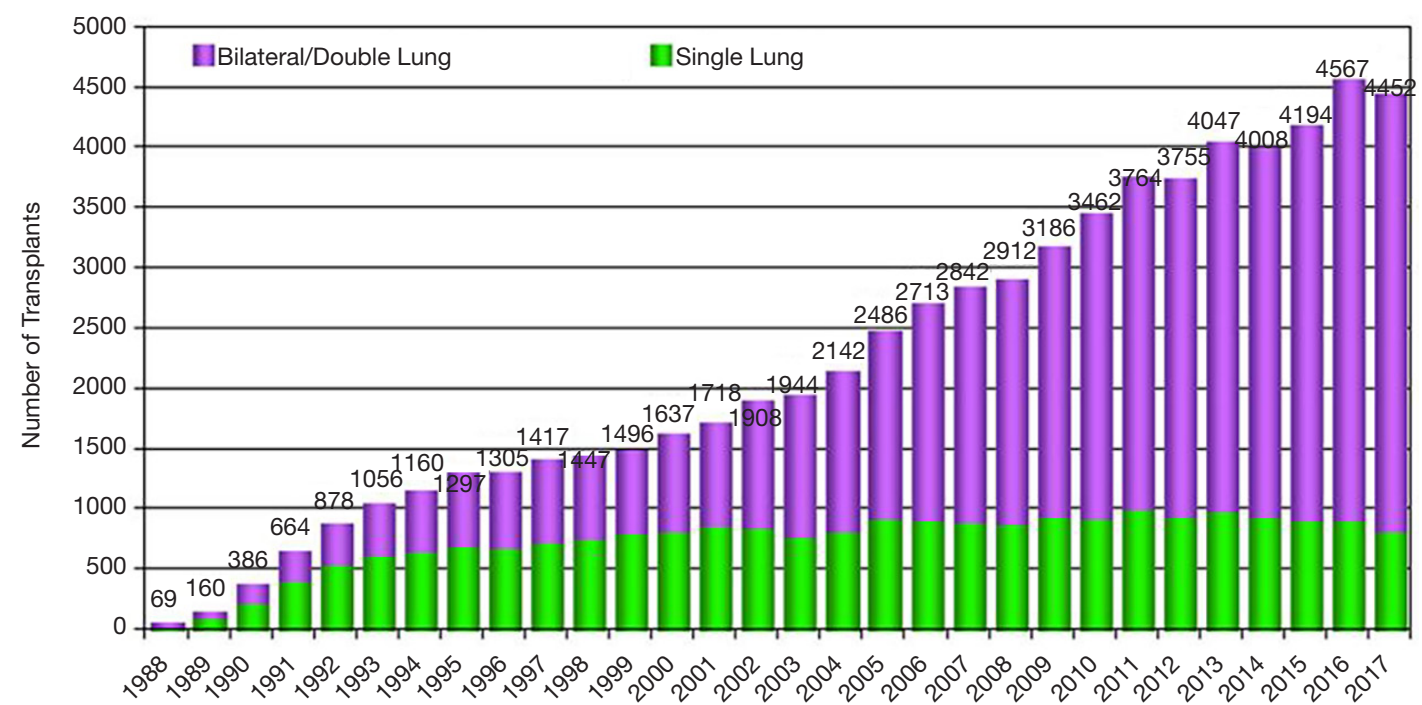

Figure 1 Number of lung transplants reported to ISHLT from year 1988-2017 [reproduced with permission from (2)].

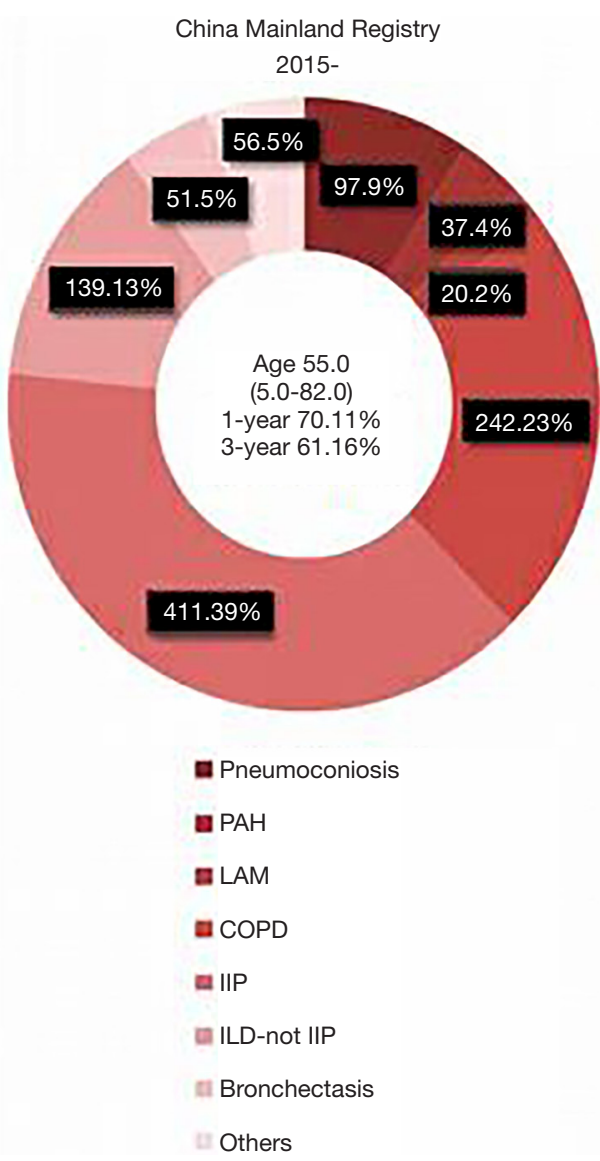

Figure 2 Indications for lung transplantation in Mainland China [reproduced with permission from (5)].
China. If one uses the USA as a yardstick, there are about 2,500 lung transplants or 10 times the number of lung transplants in the USA for a population that is about one quarter that of China (7). Therefore, there might be a 40fold greater ceiling for the number of lung transplants in China. This is theoretic of course, and one of many issues, as in all countries, is who pays for this high cost care? This is especially important in countries where cost effective considerations might result in healthcare resources being diverted to more prevalent diseases where there is greater overall societal benefit. Indeed, it does not appear that everything is paid for by the government as the review does mention the financial difficulties of certain groups of patients, specifically those with occupational lung disease of whom there appears to be a disproportionately high number. Another group of disproportionately represented patients are those with lymphangioleiomyomatosis (LAM); if our visual color discrimination is accurate (Figure 2, adopted from figure 3 from reference 5), then it appears that the proportion of LAM lung transplants ranges from $8-39 \%$ (5). Comparatively in the ISHLT database, LAM constitutes less than $1 \%$ of all transplants. To our knowledge, there isn't a higher preference of LAM in China (personal communication, Dr. Joel Moss, National Institute of Health, USA). Therefore, this might reflect a referral bias where younger females are more likely to be referred for lung transplantation. This then highlights the unmet need for transplants among diseases that are likely much 
more common in China, including IPF and COPD. This high number of LAM patients does however underscore the opportunities to do clinical trials in post-lung transplant recipients, an area of research which is sorely lacking, especially randomized, double-blind trials (RCTs). Examples of future China based RCTs might include single versus bilateral lung transplantation or the role of early sirolimusbased immunosuppression (after 3 months) in LAM recipients. Chronic lung allograft dysfunction, specifically the bronchiolitis obliterans syndrome phenotype, remains the Achilles' heel of transplantation worldwide. If the number of transplants in China do increase significantly, will there be opportunity for China to take the lead or at least contribute substantively to future therapeutic trials in this area of unmet need?

One other area where we can learn from the Chinese system is in the transportation of organs which appears to be centralized, highly orchestrated and prioritized, facilitated by the China Lung Transplantation Alliance. Ideally, this "green channel" for long-distance organ transportation could be coupled with a network of procurement surgeons throughout China. Together with the availability of ex-vivo lung perfusion, such a system might enable greater organ availability to accommodate many more patients with this potentially life-saving procedure. Perhaps such a strategy could bring lung transplantation to the reach of the less populated parts of the country, like in the west and far north-east regions that currently seem to have poor access. It also appears that there is a great emphasis on training medical staff both locally and abroad, a noble effort to increase the human resources required in expanding current lung transplant centers and developing new ones.

The authors cite and expand on other potential reasons for continued growth and success of lung transplantation in China over the last few years and these are worth summarizing. One is the well-validated multidisciplinary approach in the care of patients, from the pre-transplant period all the way through their post-transplant course. A strong emphasis seems to have been placed on collaboration, not only between different departments within the lung transplant centers, but also between different centers within the country. Moreover, initiation of academic collaboration with centers outside of Mainland China including Macau, Taiwan, Saudi Arabia and Philippines is a welcome move. Another important aspect of lung transplant growth and development is the legal system construct which guarantees organ procurement and utilization. Since the establishment of official criteria for brain death by the Chinese Ministry of
Health in 2003, there seem to have been significant steps to provide a legal basis to support qualified transplant centers and limit the illegal use of organs. The China Organ Transplant Response System, the official organ allocation system, has seemingly been effective in ensuring fairness, efficiency and safety of organ distribution. Similarly, the announcement on January 01, 2015 of voluntary donated organs to be the sole legal source of transplantable organs was another important step to regulate organ donation and transplantation. Data to support the enactment of this announcement will be very helpful to demonstrate transparency of organ donation in the country, an issue that has occasionally been questioned in the past. On the other hand, use of public media to educate the masses and raise awareness on organ donation will be of paramount importance in ensuring long-term growth of lung transplantation. Collaboration between transplant centers and patient groups like the LAM China foundation and pulmonary hypertension support groups will also enable achievement of this goal.

It is apparent that China is emerging as a leader in lung transplantation in Asia. It is gratifying that the lung transplant community in Mainland China is reaching out to other Asian countries for collaboration as a part of Asian Society of Transplantation. To our knowledge, the data for lung transplantation in China is not reported to the ISHLT registry, an important next step we believe in bringing the development of lung transplantation in China into the global spotlight. This would facilitate sharing and comparing the China experience with the rest of the world and might enable important lessons for the global lung transplant community.

\section{Acknowledgments}

Funding: None.

\section{Footnote}

Conflicts of Interest: The authors have no conflicts of interest to declare.

Ethical Statement: The authors are accountable for all aspects of the work in ensuring that questions related to the accuracy or integrity of any part of the work are appropriately investigated and resolved.

Open Access Statement: This is an Open Access article 
distributed in accordance with the Creative Commons Attribution-NonCommercial-NoDerivs 4.0 International License (CC BY-NC-ND 4.0), which permits the noncommercial replication and distribution of the article with the strict proviso that no changes or edits are made and the original work is properly cited (including links to both the formal publication through the relevant DOI and the license). See: https://creativecommons.org/licenses/by-nc-nd/4.0/.

\section{References}

1. Toronto Lung Transplant Group. Unilateral lung transplantation for pulmonary fibrosis. N Engl J Med 1986; 314:1140-5.

2. Chambers DC, Cherikh WS, Harhay MO, et al. The International Thoracic Organ Transplant Registry of the International Society for Heart and Lung Transplantation: Thirty-sixth adult lung and heart-lung transplantation

Cite this article as: Aryal S, Nathan SD. Lung transplantation in China: a firm foundation for a solid future. Ann Transl Med 2020;8(6):265. doi: 10.21037/atm.2020.02.165
Report-2019; Focus theme: Donor and recipient size match. J Heart Lung Transplant 2019;38:1042-55.

3. Samano MN, Pêgo-Fernandes PM. Building a Lung Transplant Program. Clinics (Sao Paulo) 2015;70:773-4.

4. Sunder T, Ramesh TP, Kumar KM, et al. Lung Transplant: The Indian experience and suggested guidelines-part 1 selection of the donor and recipient. Journal of the Practice of Cardiovascular Sciences 2018;4:88-95.

5. Wu B, Hu C, Chen W, et al. China lung transplantation developing: past, present and future. Ann Transl Med 2020;8:41.

6. Chen J, Mao W, Zhen M. First Chinese National Registry Report of Lung Transplantation in 2016. Transplantation 2018;102:S838.

7. Valapour M, Lehr CJ, Skeans MA, et al. OPTN/SRTR 2017 Annual Data Report: Lung. Am J Transplant 2019;19:404-84. 